\title{
Effects of Cu Self-Capping and Ta Capping on Nanometer-Sized Cu Films Sputter-Deposited on $\beta$-Ta
}

\author{
Hisanori Tanimoto*, Takayuki Sugimori, Shoichiro Kumamoto, \\ Hazuki Matsui and Hiroshi Mizubayashi \\ Graduate School of Pure and Applied Sciences, University of Tsukuba, Tsukuba 305-8573, Japan
}

$\mathrm{The} \mathrm{Cu}(111)$ texture evolution in Cu films sputter-deposited on 35-nm $\beta$-Ta barrier layers on $\mathrm{Si}(100)(\mathrm{Ta} / \mathrm{Cu})$ and in those capped by 5 -nm $\mathrm{Ta}(\mathrm{Ta} / \mathrm{Cu} / \mathrm{Ta})$ were studied by X-ray diffraction (XRD). The $\mathrm{Cu}$ thicknesses $\left(t_{\mathrm{Cu}}\right)$ ranged from 5 to $500 \mathrm{~nm}$. For Ta/Cu, the intensity of the $\mathrm{Cu}$ 111 reflection exhibited a step-like increase for $t_{\mathrm{Cu}}$ between 22 and $33 \mathrm{~nm}$, indicating that subsequent deposition of $\mathrm{Cu}$ caused the $\mathrm{Cu}(111)$ texture evolution in the already-deposited $\mathrm{Cu}$ film (Cu self-capping effect). For $\mathrm{Ta} / \mathrm{Cu} / \mathrm{Ta}$, the 5-nm Ta capping caused the $\mathrm{Cu}(111)$ texture evolution in the already-deposited $\mathrm{Cu}$ films for $t_{\mathrm{Cu}}$ between 10 and $30 \mathrm{~nm}$ (Ta capping effect). These capping effects indicate that the texture evolution took place at room temperature in nanocrystalline $\mathrm{Cu}$ films. The capping effects and the initial growth stage of $\mathrm{Cu}$ on $\beta$-Ta are discussed as they relate to $\mathrm{Ta}$ and $\mathrm{Cu}$ interfacial and grain boundary energies in the nanocrystalline structures. [doi:10.2320/matertrans.M2010286]

(Received August 30, 2010; Accepted October 15, 2010; Published December 1, 2010)

Keywords: copper, tantalum, thin film, capping effect, interface energy, grain boundary, nanocrystalline structurte

\section{Introduction}

Understanding the properties and structures of $\mathrm{Cu}$ thin films deposited on barrier films made from materials such as Ta and TiN is important for developing high-performance microelectronic devices. The $\mathrm{Cu}-\mathrm{Ta}$ system is a typical immiscible example; therefore, its microstructure is also of great interest from a scientific perspective. Many studies have focused on the resistivity and electromigration, ${ }^{1-3)}$ mechanical properties, ${ }^{4-6)}$ and microstructures ${ }^{7-10)}$ of $\mathrm{Cu}$ films formed on Ta. Interconnections between films with sizes of less than a few tens of nanometers, such as nanometer-thick $\mathrm{Cu}$ films on nanometer-thick Ta barrier layers, require control of their microstructures for use as strong heterogeneous filmbarrier systems. The growth behavior is very important for the preparation of nanometer-thick metallic films, and it depends on the interfacial state between the film and its underlayer. There are three well-known modes of growth for metallic thin films prepared by deposition: a layer-by-layer growth (Frank-van der Merwe (FM) mode), a three-dimensional-island growth (Volmer-Weber (VM) mode), and a transitional mode from the initial layer-by-layer growth to the three-dimensional-island growth with increasing deposition thickness (Stranski-Krastanov (SK) mode). For $\mathrm{Cu}$ growth on a clean Ta surface, the formation of approximately one conformal $\mathrm{Cu}$ monolayer with high thermal stability has been reported from experiments ${ }^{7,11,12)}$ and calculations. ${ }^{10,13,14)}$ These reports suggest that $\mathrm{Cu}$ grows in the SK growth mode on Ta. The crystallographic texture and elastic property of $\mathrm{Cu}$ films sputter-deposited on Ta are expected to change with the $\mathrm{Cu}$ thickness in the nanometer-thick range.

The $\mathrm{Cu}$ thickness dependence of the crystallographic texture and elastic property of $\mathrm{Cu}$ films sputter-deposited on 35-nm-thick Ta barrier films $(\mathrm{Ta} / \mathrm{Cu})$ and 5-nm-thick Ta capped films $(\mathrm{Ta} / \mathrm{Cu} / \mathrm{Ta})$ were studied for $\mathrm{Cu}$ thicknesses

*Corresponding author, E-mail: tanimoto@ims.tsukuba.ac.jp between 10 and $1000 \mathrm{~nm}$ in our previous investigations. ${ }^{4,15)}$ Reed-shaped Si substrates were used to measure the elastic property of the $\mathrm{Cu}$ thin films using the complex reed vibration method. ${ }^{16,17)}$ After intensive chemical etching, the Si substrates exhibited undulated surfaces, and the deposited 35nm-thick Ta barrier films were composed of equilibrium $\alpha$ Ta and nonequilibrium $\beta$-Ta. ${ }^{4)}$ For $\mathrm{Cu}$ film thicknesses $\left(t_{\mathrm{Cu}}\right)$ below $\sim 80 \mathrm{~nm}$, both the crystallographic texture and elastic property exhibited considerable changes with the $\mathrm{Cu}$ film thickness, as well as after Ta capping. For example, the in-plane Young's modulus of the $\mathrm{Cu}$ films decreased with $t_{\mathrm{Cu}}$ for $\mathrm{Ta} / \mathrm{Cu}$ and was enhanced after 5-nm Ta-capping for $\mathrm{Ta} / \mathrm{Cu} / \mathrm{Ta}$. The $\mathrm{Cu}(111)$ plane distance $\left(d_{\mathrm{Cu} 111}\right)$ normal to the film surface decreased with $t_{\mathrm{Cu}}$ for $\mathrm{Ta} / \mathrm{Cu}(\sim 0.3 \%$ from the bulk value at $t_{\mathrm{Cu}}$ of $\left.20 \mathrm{~nm}\right)$, and such a decrease in $d_{\mathrm{Cu} 111}$ almost disappeared after 5-nm Ta capping for $\mathrm{Ta} / \mathrm{Cu} / \mathrm{Ta}$. Because the $\mathrm{Cu}$ thin films were not only prepared on the barrier film but also capped or surrounded by the barrier layers in the microelectronic devices, it is important to understand these phenomena from the previous work.

During Ta deposition on $\mathrm{Si}$, the nonequilibrium $\beta$-Ta phase is preferentially formed by sputter-deposition on $\mathrm{Si}$ or $\mathrm{SiO}_{2}{ }^{12,18-22)}$ In our previous work, the Ta barrier layers deposited on $\mathrm{Si}$ reed substrates with undulated surfaces consisted of an equilibrium $\alpha$-Ta phase and $\beta$-Ta phase. ${ }^{4)}$ In contrast, the Ta barrier layers deposited on Si reed substrates with a mirror surface consisted solely of the $\beta$-Ta phase. ${ }^{15)}$ On the other hand, on $\alpha$-Ta, but not on $\beta$-Ta, the formation of a superstructured $\mathrm{Cu}$ layer has been reported in a recent computer simulation study of the deposition of an fcc $\mathrm{Cu}$ film on Ta. ${ }^{10)}$ These results indicate that further study of the microstructure of $\mathrm{Cu}$ films deposited on $\beta$-Ta films formed on $\mathrm{Si}$ substrates with a mirror surface is technologically and scientifically relevant. In the present study, we used Si wafers with a mirror surface as substrates and investigated the $\mathrm{Cu}$ thickness dependence of the microstructure of nanometerthick $\mathrm{Cu}$ films deposited on $\beta$-Ta and of those capped with 5- 
$\mathrm{nm}$ thick Ta by X-ray diffraction (XRD). For $t_{\mathrm{Cu}}<100 \mathrm{~nm}$, all $\mathrm{Cu}$ films exhibited a preferred (111) texture in which the (111) planes of most crystallites were parallel to the flat surface of the sample. For $\mathrm{Ta} / \mathrm{Cu}$, the $\mathrm{Cu}$-thickness dependence of the intensity of the 111 reflection exhibited a step-like increase at $t_{\mathrm{Cu}}$ between 22 and $33 \mathrm{~nm}$, indicating spontaneous improvement of the preferred (111) texture in the alreadydeposited $\mathrm{Cu}$ films by subsequent deposition of $\mathrm{Cu}(\mathrm{Cu}$ selfcapping effect). For $\mathrm{Ta} / \mathrm{Cu} / \mathrm{Ta}$, the spontaneous improvement of the preferred (111) texture in the already-deposited $\mathrm{Cu}$ films by 5 -nm-thick Ta capping occurred at $t_{\mathrm{Cu}}$ between 10 and $30 \mathrm{~nm}$ (Ta capping effect).

\section{Experimental Procedure}

$\mathrm{Si}$ (100) wafers ( $\phi=2$ in., 0.4-mm thick) that were mirrorpolished on one side, were cut into rectangular pieces having a length and width of $1.3 \mathrm{~cm}$ and $2 \mathrm{~cm}$, respectively. These substrates were rinsed with ethanol in an ultrasonic bath, and organic contamination was chemically removed using a mixed solution of $\mathrm{H}_{2} \mathrm{SO}_{4}$ and $\mathrm{H}_{2} \mathrm{O}_{2}$. Finally, the surfaces of the $\mathrm{Si}$ substrates were terminated by hydrogen using a dilute HF solution.

Deposition of $\mathrm{Ta}$ and $\mathrm{Cu}$ was carried out using DC magnetron sputtering equipment (ULVAC MPS-2000) under $1.3 \times 10^{-1} \mathrm{~Pa} \mathrm{Ar}$ at ambient temperatures. The nominal purity of $\mathrm{Ar}$ was $99.9999 \%$. The distance between the substrate and the target was $200 \mathrm{~mm}$. We applied $50 \mathrm{~W}$ each of $\mathrm{rf}$ and dc power to the coil for helicon wave generation and to the target (Ta $(99.95 \%)$ or $\mathrm{Cu}(99.999 \%), \phi=2 \mathrm{in}$.), respectively. The film growth rates of $\mathrm{Ta}$ and $\mathrm{Cu}$ were approximately 2 and $5 \mathrm{~nm} / \mathrm{min}$, respectively. The thicknesses of the deposited $\mathrm{Ta}$ and $\mathrm{Cu}$ were determined based on the weight change of an $\mathrm{Al}$ foil located near the substrate. For $\mathrm{Ta} / \mathrm{Cu}$, a 35-nm-thick Ta barrier layer was deposited on the $\mathrm{Si}$ substrate, and a $\mathrm{Cu}$ film with the desired thickness was subsequently deposited on the Ta barrier layer without breaking the Ar atmosphere. For $\mathrm{Ta} / \mathrm{Cu} / \mathrm{Ta}$, a 5-nm-thick Ta capping layer was further deposited on the $\mathrm{Cu}$ film without breaking the Ar atmosphere. To examine the morphology of the Ta barrier layer, a 35-nm-thick Ta barrier layer was deposited on the $\mathrm{Si}$ substrate (Ta barrier alone). A single $\mathrm{Cu}$ (111) crystal with a diameter of $10 \mathrm{~mm}$ and thickness of $0.5 \mathrm{~mm}$ was used as a model sample with a fully preferred oriented state. $\mathrm{Cu}$ pellets were prepared by compacting $\mathrm{Cu}$ powder (10- $\mu \mathrm{m}$ grains) for reference samples of polycrystalline bulk $\mathrm{Cu}$ with fully random textures. The porosity of the $\mathrm{Cu}$ pellets was determined from their weight and dimensions.

XRD measurements in the $2 \theta-\theta$ scan mode were performed with $\mathrm{Cu}-\mathrm{K} \alpha$ radiation $(40 \mathrm{keV}, 30 \mathrm{~mA}$, Rigaku RINT 2100). The scattering vector was normal to the film. The axes of $2 \theta$ and $\theta$ were adjusted according to the maximum $\mathrm{Cu} 111$ reflection intensity prior to the $2 \theta-\theta$ scan, and a $1^{\circ}$ divergence slit was used. The 111 reflection from the $\mathrm{Cu}$ single crystal was used as the instrumental line broadening for an estimation of the mean grain size. Reflections from $\mathrm{Si}$ powders placed on the film surface were used as references for the $2 \theta$ scale. XRD measurements in the $\omega$ scan mode ( $2 \theta$ scan with $\theta$ at the Bragg position of the $\mathrm{Cu} 111$ reflection) were also conducted for several samples.

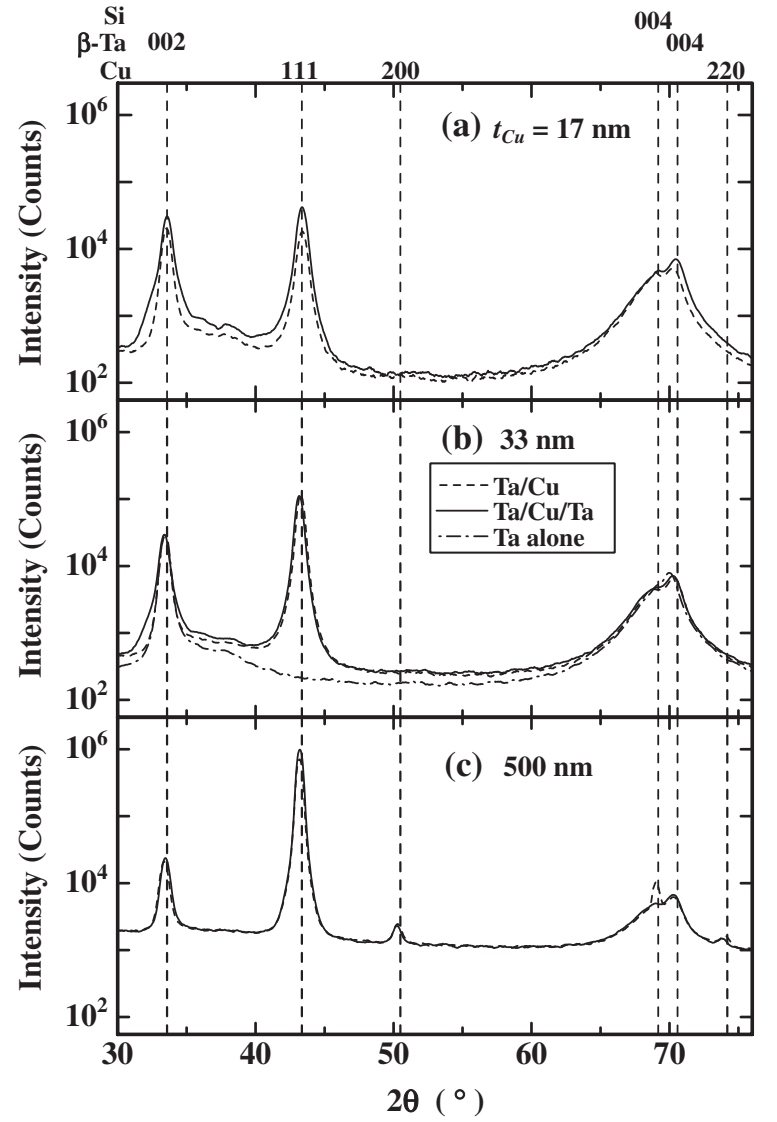

Fig. 1 X-ray diffraction patterns for $\mathrm{Ta} / \mathrm{Cu}$ (dashed lines) and $\mathrm{Ta} / \mathrm{Cu} / \mathrm{Ta}$ (solid lines) for $\mathrm{Cu}$ film thicknesses of (a) $17 \mathrm{~nm}$, (b) $33 \mathrm{~nm}$, and (c) $500 \mathrm{~nm}$. In (b), the pattern for the Ta barrier alone $(35 \mathrm{~nm})$ is also shown (dotted/dashed line). The broad peak at $\sim 2 \theta=69.2^{\circ}$ is the Si 400 reflection from the substrate (the $\mathrm{Si}\langle 100\rangle$ direction is off from the scattering vector by $\sim 1^{\circ}$ ).

\section{Results and Discussion}

Figures 1(a)-(c) show example XRD spectra for the $\mathrm{Ta} / \mathrm{Cu}$ and $\mathrm{Ta} / \mathrm{Cu} / \mathrm{Ta}$ samples deposited on mirror $\mathrm{Si}$ substrates with $t_{\mathrm{Cu}}$ of 17,33 , and $500 \mathrm{~nm}$, respectively. The spectrum for the sample composed of the Ta barrier alone is also shown in Fig. 1(b). There were no reflections of $\alpha$-Ta; only the 002 and 004 reflections of $\beta$-Ta were observed, indicating that the 35-nm-thick Ta barrier layer consisted of $\beta$-Ta with a highly preferred (001) texture, in which the (001) planes of most crystallites were parallel to the flat surface of the film. In the XRD spectra for $\mathrm{Ta}$ in $\mathrm{Ta} / \mathrm{Cu}$ and $\mathrm{Ta} / \mathrm{Cu} / \mathrm{Ta}$, only the 002 and 004 reflections of $\beta$-Ta were observed for all $\mathrm{Ta} / \mathrm{Cu}$ and $\mathrm{Ta} / \mathrm{Cu} / \mathrm{Ta}$ samples with $t_{\mathrm{Cu}}$ between 5 and $500 \mathrm{~nm}$. This indicates that the $35-\mathrm{nm}$-thick Ta barrier layers remained as $\beta$-Ta with the highly preferred (001) texture after $\mathrm{Cu}$ film deposition and that the 5-nm Ta capping layers also had the same texture. Figures 1(a) and (b) show that the base of the $\beta$-Ta 002 reflection for $\mathrm{Ta} / \mathrm{Cu} / \mathrm{Ta}$ with $t_{\mathrm{Cu}}$ of 17 or $33 \mathrm{~nm}$ was broader than that for $\mathrm{Ta} / \mathrm{Cu}$ because of the overlap of the additional reflection from the 5-nm Ta capping layer. In contrast, Fig. 1(c) shows that the base of the $\beta$-Ta 002 reflection due to the 5-nm-thick Ta capping layer was smeared by increased background scattering from the 500nm-thick $\mathrm{Cu}$ film. 
The XRD spectra for $\mathrm{Cu}$ in $\mathrm{Ta} / \mathrm{Cu}$ with $t_{\mathrm{Cu}}$ of 17 and $33 \mathrm{~nm}$ (Figs. 1(a) and (b)) show that only the 111 reflection of fcc $\mathrm{Cu}$ was seen in the $2 \theta$ range shown here, and only the $\mathrm{Cu} 222$ reflection was seen in the $2 \theta$ range of $76-100^{\circ}$ (not shown here). For $\mathrm{Ta} / \mathrm{Cu}$ with $t_{\mathrm{Cu}}$ of $500 \mathrm{~nm}$, minor $\mathrm{Cu} 200$ and 220 reflections were observed in addition to the major $\mathrm{Cu} 111$ reflection (Fig. 1(c)). The $\mathrm{Cu} 200$ and 220 reflections were detected for $t_{\mathrm{Cu}}>200 \mathrm{~nm}$. At $t_{\mathrm{Cu}}$ of $17 \mathrm{~nm}$, the profile of the $\mathrm{Cu} 111$ reflection in $\mathrm{Ta} / \mathrm{Cu} / \mathrm{Ta}$ was almost the same as that in $\mathrm{Ta} / \mathrm{Cu}$ (Fig. 1(a)). However, the peak intensity of the $\mathrm{Cu}$ 111 reflection was higher in $\mathrm{Ta} / \mathrm{Cu} / \mathrm{Ta}$ than in $\mathrm{Ta} / \mathrm{Cu}$. The latter feature suggests that the 5-nm-thick Ta capping caused some modification of the crystallographic texture in the already-deposited $\mathrm{Cu}$ film. In contrast, at $t_{\mathrm{Cu}}$ of $33 \mathrm{~nm}$, both the profile and intensity of the $\mathrm{Cu} 111$ reflection showed good agreement between $\mathrm{Ta} / \mathrm{Cu}$ and $\mathrm{Ta} / \mathrm{Cu} / \mathrm{Ta}$ (Fig. 1(b)), i.e., there was no modification of the crystallographic texture in the already-deposited $\mathrm{Cu}$ film by the 5-nm-thick Ta capping layer. At $t_{\mathrm{Cu}}$ of $500 \mathrm{~nm}$, the major $\mathrm{Cu} 111$ reflection and the minor $\mathrm{Cu} 200$ and 220 reflections in $\mathrm{Ta} / \mathrm{Cu} / \mathrm{Ta}$ were in good agreement with those in $\mathrm{Ta} / \mathrm{Cu}$ (Fig. 1(c)).

The XRD results above indicate that the present $\mathrm{Cu}$ films sputter-deposited on the $\beta$-Ta barrier layer had the highly preferred (111) texture, in which the (111) planes of most crystallites were parallel to the flat surface of the specimen. Furthermore, the degree of alignment in the preferred (111) texture of the already-deposited $\mathrm{Cu}$ films with $t_{\mathrm{Cu}}$ between 10 and $30 \mathrm{~nm}$ was modified by capping with the 5 -nm-thick Ta layer. Figure 2 shows the dependence of the integral intensity of the $\mathrm{Cu} 111$ reflection $\left(I_{111}\right)$ for $\mathrm{Ta} / \mathrm{Cu}$ and $\mathrm{Ta} / \mathrm{Cu} / \mathrm{Ta}$ on the value of $t_{\mathrm{Cu}}$. From the mass absorption of the X-ray, the dependence of $I_{111}$ on $t_{\mathrm{Cu}}$ can be expressed by the following equation: ${ }^{23)}$

$$
I=I_{0} \exp \left(-2 \mu t_{\mathrm{Cu}} / \sin \theta_{111}\right)
$$

where $I_{0}$ is the intensity of the incident X-ray; $\mu$, the mass absorption coefficient of $\mathrm{Cu}-\mathrm{K} \alpha$ radiation for $\mathrm{Cu}$; and $\theta_{111}$, the Bragg angle for the $\mathrm{Cu} 111$ reflection. The intensity of the $\mathrm{XRD}$ reflection depends on the dimensions as well as on the crystallinity of a sample. The $t_{\mathrm{Cu}}$ dependence of $I_{111}$ for the (111) single crystalline state was estimated from the $I_{111}$ measured for the $\mathrm{Cu}(111)$ single crystal sample $(\phi=10 \mathrm{~mm}$, $0.5-\mathrm{mm}$ thick) under the same measurement conditions, based on eq. (1). Figure 2 shows the result as a solid line as a guide for the fully preferred (111) texture state. The dotted/ dashed line shown in Fig. 2 denotes the dependence of $I_{111}$ on $t_{\mathrm{Cu}}$ for the fully random-oriented polycrystalline state, in which $I_{111}$ for $\mathrm{Cu}$ pellets was measured under the same conditions, and the $t_{\mathrm{Cu}}$ dependence was estimated based on eq. (1) as well as the influence of porosity on intensity.

For $\mathrm{Ta} / \mathrm{Cu}$ samples shown in Fig. 2, all of the $I_{111}$ data are between the values expected for the fully (111) textured and fully random states. The slope of the $t_{\mathrm{Cu}}$ dependence of $I_{111}$ in $\mathrm{Ta} / \mathrm{Cu}$ at $t_{\mathrm{Cu}}$ between 33 and $100 \mathrm{~nm}$ agreed well with that expected from eq. (1). The $I_{111}$ value observed at $t_{\mathrm{Cu}}$ of $500 \mathrm{~nm}$ exhibited a downward deviation from the line extrapolating the $t_{\mathrm{Cu}}$ dependence of $I_{111}$ between 33 and $100 \mathrm{~nm}$ in Fig. 2. This was associated with the appearance and increase in the $\mathrm{Cu} 200$ and 220 reflections at $t_{\mathrm{Cu}}>$ $200 \mathrm{~nm}$, as mentioned previously. For $t_{\mathrm{Cu}}>22 \mathrm{~nm}$, the slope

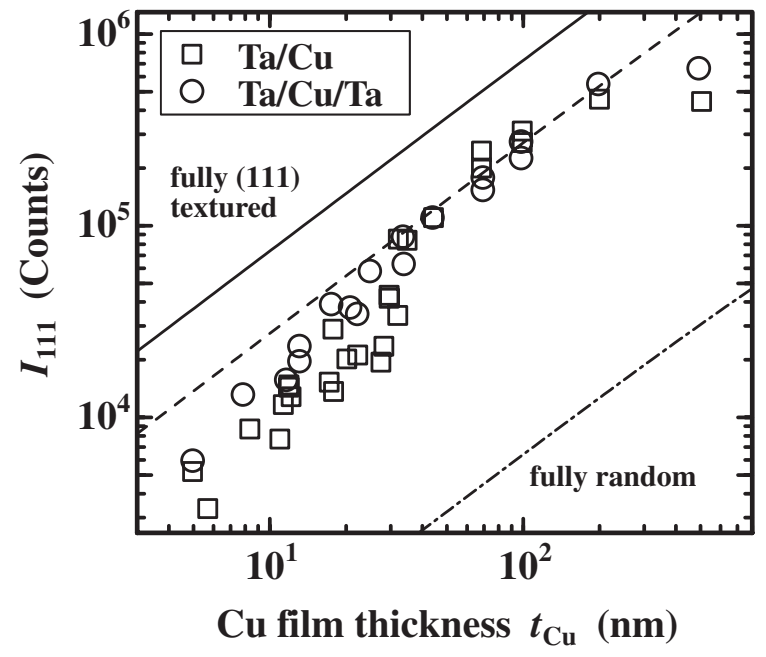

Fig. $2 t_{\mathrm{Cu}}$ dependencies for $I_{111}$. The solid line and dotted/dashed lines show the $t_{\mathrm{Cu}}$ dependence expected for the $\mathrm{Cu}(111)$ single crystalline state and the fully random-oriented polycrystalline state, respectively. The dashed line shows the results of fitting eq. (1) using the observed data at $t_{\mathrm{Cu}}$ between 33 and $100 \mathrm{~nm}$.

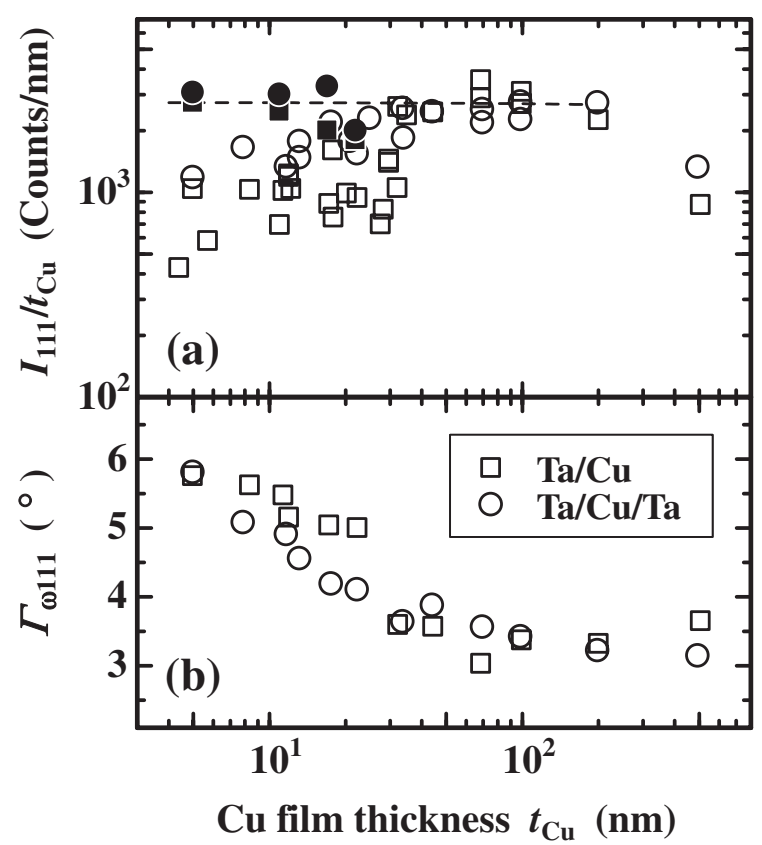

Fig. 3 (a) $t_{\mathrm{Cu}}$ dependencies of $I_{111}$ normalized by $t_{\mathrm{Cu}}$ (open symbols) and those revised by accounting for differences in the preferred texture (filled symbols, see text for details). (b) $t_{\mathrm{Cu}}$ dependence of the full width at half maximum for the peak in Fig. $4\left(\Gamma_{\omega 111}\right)$.

of the $t_{\mathrm{Cu}}$ dependence of $I_{111}$ for $\mathrm{Ta} / \mathrm{Cu}$ exhibits good agreement with that for $t_{\mathrm{Cu}}$ between 33 and $100 \mathrm{~nm}$. However, the $I_{111}$ values for $t_{\mathrm{Cu}}<22 \mathrm{~nm}$ were about onehalf of those expected from the $t_{\mathrm{Cu}}$ dependence of $I_{111}$ between 33 and $100 \mathrm{~nm}$. Figure 3(a) shows $I_{111}$ normalized by $t_{\mathrm{Cu}}\left(I_{111} / t_{\mathrm{Cu}}\right)$, and a step-like decrease at $t_{\mathrm{Cu}}$ between 22 and $33 \mathrm{~nm}$ is clearly seen for $\mathrm{Ta} / \mathrm{Cu}$. The data for $\mathrm{Ta} / \mathrm{Cu} / \mathrm{Ta}$ exhibit a gradual increase in $I_{111} / t_{\mathrm{Cu}}$ at $t_{\mathrm{Cu}}$ between 10 and $30 \mathrm{~nm}$ because of the 5 -nm-thick Ta capping.

Figure 4 shows the XRD spectra for the $\mathrm{Cu} 111$ reflection in the $\omega$ scan mode. The integrated intensity was normalized 


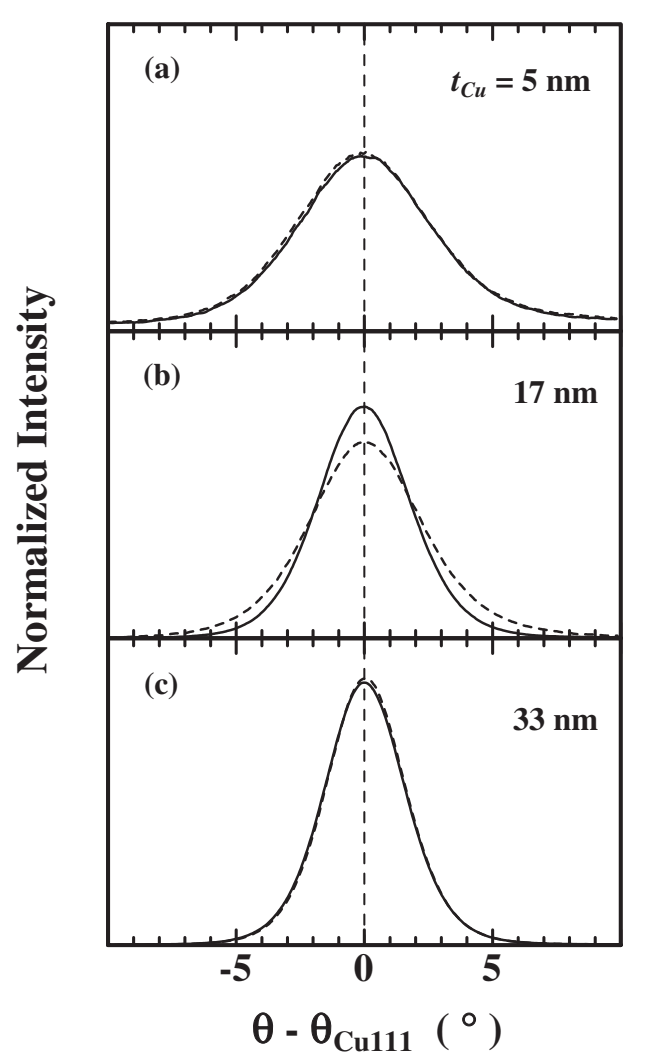

Fig. 4 Profiles of X-ray diffraction peaks in the $\omega$-scan mode for the $\mathrm{Cu}$ 111 reflection of $\mathrm{Ta} / \mathrm{Cu}$ (dashed lines) and $\mathrm{Ta} / \mathrm{Cu} / \mathrm{Ta}$ (solid lines) at $t_{\mathrm{Cu}}$ of (a) $5 \mathrm{~nm}$, (b) $17 \mathrm{~nm}$, and (c) $33 \mathrm{~nm}$.

for all peaks. A broader peak in the $\omega$ scan mode indicates weaker alignment in the preferred (111) orientation of the crystallites. At $t_{\mathrm{Cu}}$ of $5 \mathrm{~nm}$, the peak profiles for $\mathrm{Ta} / \mathrm{Cu}$ and $\mathrm{Ta} / \mathrm{Cu} / \mathrm{Ta}$ were broad and nearly identical. At $t_{\mathrm{Cu}}$ of $17 \mathrm{~nm}$, the peak profiles for both $\mathrm{Ta} / \mathrm{Cu}$ and $\mathrm{Ta} / \mathrm{Cu} / \mathrm{Ta}$ were sharper than their counterparts at $t_{\mathrm{Cu}}$ of $5 \mathrm{~nm}$, and the peak of $\mathrm{Ta} / \mathrm{Cu} / \mathrm{Ta}$ with the 5-nm-thick Ta capping was sharper than that of $\mathrm{Ta} / \mathrm{Cu}$. At $t_{\mathrm{Cu}}$ of $33 \mathrm{~nm}$, the peak profiles for both $\mathrm{Ta} / \mathrm{Cu}$ and $\mathrm{Ta} / \mathrm{Cu} / \mathrm{Ta}$ were sharper than their counterparts at $t_{\mathrm{Cu}}$ of $17 \mathrm{~nm}$, but further sharpening due to the 5-nm-thick Ta capping was not observed. To evaluate the degree of alignment in the preferred (111) texture, the full width at half maximum $\left(\Gamma_{\omega 111}\right)$ was determined by assuming that the peak profile was approximated by a Gaussian function. The $t_{\mathrm{Cu}}$ dependence of $\Gamma_{\omega 111}$ is shown in Fig. 3(b). As $t_{\mathrm{Cu}}$ increased, $\Gamma_{\omega 111}$ for $\mathrm{Ta} / \mathrm{Cu}$ exhibited a gradual decline for $t_{\mathrm{Cu}}<22 \mathrm{~nm}$, a step-like decrease at $t_{\mathrm{Cu}}$ between 22 and $33 \mathrm{~nm}$, and then saturation at $\sim 3^{\circ}$ for larger $t_{\mathrm{Cu}}$. After the 5-nm-thick Ta capping, $\Gamma_{\omega 111}$ for $\mathrm{Ta} / \mathrm{Cu} / \mathrm{Ta}$ exhibited a gradual decrease to $\sim 3^{\circ}$ with increasing $t_{\mathrm{Cu}}$. In other words, peak sharpening in the $\omega$ scan mode occurred at $t_{\mathrm{Cu}}$ between 10 and $30 \mathrm{~nm}$ after the 5-nm-thick Ta capping. Apparently, the lack of Ta capping effects on $\Gamma_{\omega 111}$ at $t_{\mathrm{Cu}}>30 \mathrm{~nm}$ was associated with saturation of the $\Gamma_{\omega 111}$ sharpening at $\sim 3^{\circ}$ for both $\mathrm{Ta} / \mathrm{Cu}$ and $\mathrm{Ta} / \mathrm{Cu} / \mathrm{Ta}$.

Because a divergence slit of $1^{\circ}$ was used in the present XRD measurements, the crystallites involved in the 111 reflection peak in the $2 \theta-\theta$ scan mode were those whose $\langle 111\rangle$ directions were within $0.5^{\circ}$ from the scattering vector. That is, the area fraction within $0.5^{\circ}$ from the top of the peak in the $\omega$ scan peak $(R)$ is the fractional ratio of the crystallites contributing to $I_{\mathrm{Cu} 111}$ in the present $2 \theta-\theta$ scan mode. In Fig. 3(a), the filled symbols for $t_{\mathrm{Cu}}<33 \mathrm{~nm}$ are the $I_{111} / t_{\mathrm{Cu}}$ values calibrated using $R$ at a given $t_{\mathrm{Cu}}$ and normalized by $R_{33}$ at $t_{\mathrm{Cu}}$ of $33 \mathrm{~nm}$ as a reference, $\left(I_{111} / t_{\mathrm{Cu}}\right) /\left(R / R_{33}\right)$. The $\left(I_{111} / t_{\mathrm{Cu}}\right) /\left(R / R_{33}\right)$ data for both $\mathrm{Ta} / \mathrm{Cu}$ and $\mathrm{Ta} / \mathrm{Cu} / \mathrm{Ta}$ exhibited good agreement with the mean value for $\left(I_{111} / t_{\mathrm{Cu}}\right) /\left(R / R_{33}\right)$ in $\mathrm{Ta} / \mathrm{Cu}$ between 33 and $100 \mathrm{~nm}$. The reduced $I_{111} / t_{\mathrm{Cu}}$ in $\mathrm{Ta} / \mathrm{Cu}$ at $t_{\mathrm{Cu}}<33 \mathrm{~nm}$ was associated with weaker alignment in the preferred (111) texture. In other words, alignment of the preferred (111) texture in the already-deposited $\mathrm{Cu}$ film spontaneously improved as a result of capping with the $\mathrm{Cu}$ overlayers ( $\mathrm{Cu}$ self-capping effect) at $t_{\mathrm{Cu}}$ between 22 and $33 \mathrm{~nm}$. The data for $\mathrm{Ta} / \mathrm{Cu} / \mathrm{Ta}$ in Fig. 3(a) indicate that the spontaneous improvement of the preferred (111) texture in the already-deposited $\mathrm{Cu}$ film by the 5-nm-thick Ta capping (Ta capping effect) also occurred at $t_{\mathrm{Cu}}$ between 10 and $30 \mathrm{~nm}$.

The spontaneous improvement in the alignment of the preferred (111) texture in the already-deposited $\mathrm{Cu}$ films was attributed to rotation of the crystallites. In this case, the mean rotated angle was expected to be a few degrees based on the $\Gamma_{\omega 111}$ data shown in Fig. 3(b). Spontaneous grain rotation of constituent nanocrystallites without grain growth has been reported for nanocrystalline $(n-)$ Au during plastic creep deformation under applied stress $>30 \mathrm{MPa}$ at room temperature. ${ }^{24)}$ A close similarity in the mechanisms of plastic creep deformation was reported between $n$-Au and $n-\mathrm{Cu}{ }^{25)}$ These phenomena also suggest that for the present $\mathrm{Cu}$ films in $\mathrm{Ta} / \mathrm{Cu}$ and $\mathrm{Ta} / \mathrm{Cu} / \mathrm{Ta}$, both the $\mathrm{Cu}$ self-capping and the Ta capping effects were associated with spontaneous grain rotations in the already-deposited $\mathrm{Cu}$ films. For the $\mathrm{Cu}$ selfcapping, the driving force for spontaneous rotation was attributed to the self-adjustment of the crystallographic directions in the already-deposited film induced by lateral growth of the crystallites in the capping layer. When a new crystallite formed on the polycrystalline film, nucleation at the triple junctions most likely occurred. The $\langle 111\rangle$ orientations of the new crystallite formed at the triple junctions, as well as the crystallites beneath it, adjusted in one direction to reduce the mismatch between their interfaces. For the Ta capping effect, the strong interaction between $\mathrm{Cu}$ and Ta was attributed to the driving force (see below). There were no Ta capping effects at $t_{\mathrm{Cu}}<10 \mathrm{~nm}$; thus, $t_{\mathrm{Cu}}$ of $\sim 10 \mathrm{~nm}$ corresponded to the transitional thickness for initially formed islands that transitioned to a continuous film. Below $t_{\mathrm{Cu}}$ of $\sim 10 \mathrm{~nm}$, the interfacial interaction between the $\mathrm{Cu}$ films and the Ta barrier was larger than that between the $\mathrm{Cu}$ films and the Ta capping. The gradual Ta capping effect observed for $\mathrm{Ta} / \mathrm{Cu} / \mathrm{Ta}$ at $t_{\mathrm{Cu}}$ between 10 and $30 \mathrm{~nm}$ indicates that the $\beta$-Ta barrier effects on the microstructure of deposited $\mathrm{Cu}$ crystallites ceased at $t_{\mathrm{Cu}}$ of $30 \mathrm{~nm}$. The effects of the mixed Ta barrier composed of $\alpha$-Ta and $\beta$-Ta on the microstructure of deposited $\mathrm{Cu}$ crystallites continued up to $t_{\mathrm{Cu}}$ of $80 \mathrm{~nm}$, as previously mentioned. ${ }^{4,15)}$

Figure 5(a) shows the $t_{\mathrm{Cu}}$ dependence of the interlayer distance for $\mathrm{Cu}$ (111) $\left(d_{\mathrm{Cu} 111}\right)$ normal to the film surface, as determined from their respective XRD peak positions. Successive alternations in the in-plane stress from compres- 


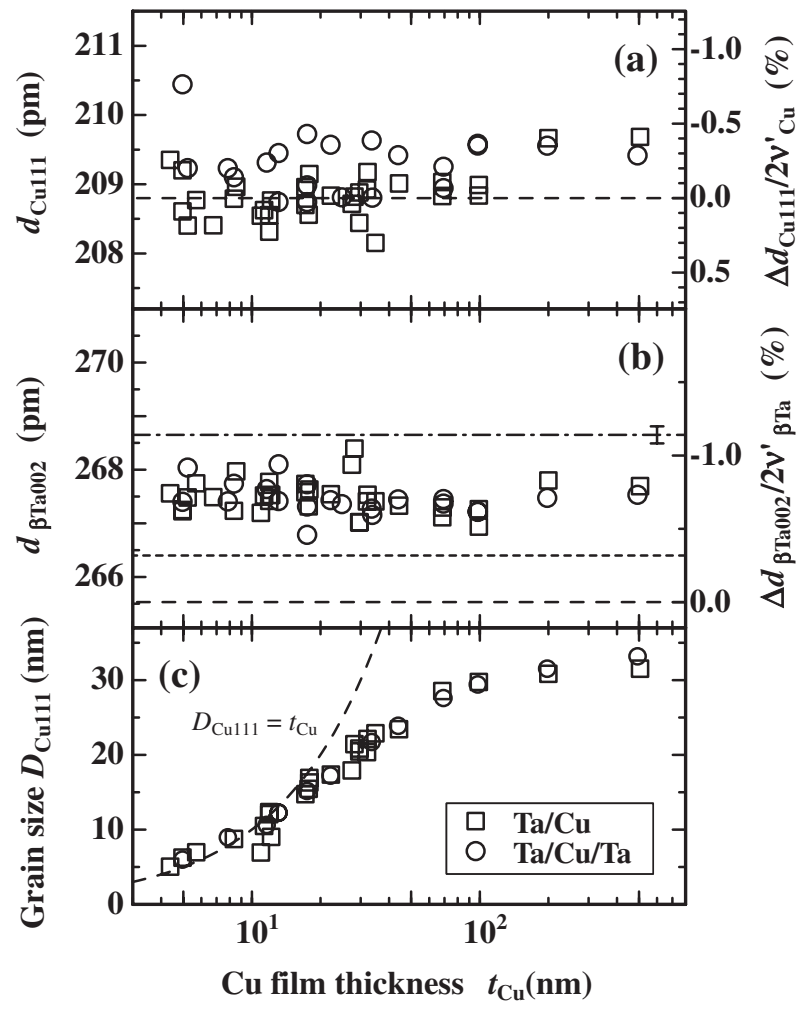

Fig. 5 (a) Dependence of the $\mathrm{Cu}(111)$ interlayer distance $\left(d_{\mathrm{Cu} 111}\right)$ on $t_{\mathrm{Cu}}$ The dashed line indicates the $d_{\mathrm{Cu} 111}$ value reported for bulk $\mathrm{Cu}$. (b) Dependence of the $\beta$-Ta $(002)$ interlayer distance $\left(d_{\beta \mathrm{Ta002}}\right)$ on $t_{\mathrm{Cu}}$. The dotted/dashed line indicates the mean value for three samples of the 35 nm-thick Ta barrier alone. The dashed lines indicate the $d_{\beta \mathrm{Ta} 002}$ values reported for a $30-\mu \mathrm{m}$-thick $\beta$-Ta film deposited on an AISI4340 steel substrate $(266.4 \mathrm{pm})^{21)}$ and for a $\sim 20-\mu \mathrm{m}$-thick $\beta$-Ta single crystal $(265.32 \mathrm{pm}){ }^{31)}$ The ordinate on the right-hand side shows the scale converted to the in-plane strain, where the $d_{\beta \mathrm{Ta} 002}$ reported for the $\beta$-Ta single crystal is considered as the bulk value. (c) Dependence of the mean grain size of the $\mathrm{Cu}$ film $\left(D_{\mathrm{Cu} 111}\right)$ on $t_{\mathrm{Cu}}$. The dashed line indicates the relationship of $D_{\mathrm{Cu} 111}=t_{\mathrm{Cu}}$

sive to tensile and back to compressive with increasing $t_{\mathrm{Cu}}$ were reported for the three-dimensional island growth mode. ${ }^{26,27)}$ Quantitatively, $d_{\mathrm{Cu} 111}$ in $\mathrm{Ta} / \mathrm{Cu}$ at $t_{\mathrm{Cu}}$ of $5 \mathrm{~nm}$ was $\sim 0.2 \%$ larger than the bulk $\mathrm{Cu}$ value, indicating that the in-plane compressive strain (or stress) in a 5-nm-thick $\mathrm{Cu}$ film on a 35 -nm-thick Ta barrier layer was $\sim 0.25 \%$ (or $0.5 \mathrm{GPa}$ ) (see the right-hand side vertical axis in Fig. 5(a)), assuming a mean Poisson ratio of 0.343 and a mean Young's modulus of $130 \mathrm{GPa}^{28)}$ along the direction of the film. As $t_{\mathrm{Cu}}$ increased above $5 \mathrm{~nm}, d_{\mathrm{Cu} 111}$ in Ta/Cu decreased to a slightly smaller value than the bulk $\mathrm{Cu}$ value, exhibited a local minimum at $t_{\mathrm{Cu}}$ of $\sim 10 \mathrm{~nm}$, and then increased slightly above the bulk $\mathrm{Cu}$ value at $t_{\mathrm{Cu}}$ above $\sim 30 \mathrm{~nm}$. The $t_{\mathrm{Cu}}$ values of the crossover points for these successive changes exhibited good agreement with those reported (i.e., the first crossover from compressive to tensile states at $t_{\mathrm{Cu}}$ between 1 and $20 \mathrm{~nm}$, and again to the compressive state at $t_{\mathrm{Cu}}$ between 4 and $40 \mathrm{~nm}$, respectively). ${ }^{26)}$ The first crossover from compressive to tensile states was observed when the initially formed islands transitioned to a continuous film. That is, when the reduction in the total surface and interface energies by contacting neighboring islands was larger than the increase in the strain energy of the resultant continuous film, the isolated islands coalesced and formed a continuous film (the zipping effect) ${ }^{29)}$ A tensile stress of $\sim 1 \mathrm{GPa}$ in the continuous film was estimated from model calculations for the zipping effect. ${ }^{30)}$ In Fig. 5(a), the compressive stress of $\sim 0.5 \mathrm{GPa}$ for $\mathrm{Cu}$ at $t_{\mathrm{Cu}}$ of $5 \mathrm{~nm}$ became nearly zero or slightly tensile for $t_{\mathrm{Cu}}$ between 10 and $30 \mathrm{~nm}$, indicating that the island-like film transitioned to a continuous film at $t_{\mathrm{Cu}}$ of $\sim 10 \mathrm{~nm}$ in the present $\mathrm{Ta} / \mathrm{Cu}$ films. $d_{\mathrm{Cu} 111}$ exhibited a local maximum at $t_{\mathrm{Cu}}$ of $\sim 30 \mathrm{~nm}$ that was slightly larger than the bulk value. Because the spontaneous improvement of the preferred (111) texture caused by the $\mathrm{Cu}$ self-capping was seen for $t_{\mathrm{Cu}}$ between 22 and $33 \mathrm{~nm}$ (Fig. 3(a)), the in-plane compressive stress may have been induced by the $\mathrm{Cu}$ self-capping effect. At $t_{\mathrm{Cu}}$ above $30 \mathrm{~nm}, d_{\mathrm{Cu} 111}$ first exhibited a slight decline to the bulk value at $t_{\mathrm{Cu}}$ of $\sim 100 \mathrm{~nm}$ and then increased slightly at $t_{\mathrm{Cu}}$ above $200 \mathrm{~nm}$. As mentioned above, the 200 and 220 reflections appeared at $t_{\mathrm{Cu}}>200 \mathrm{~nm}$. These changes in both $d_{\mathrm{Cu} 111}$ and the XRD spectra suggest that the growth mode of the $\mathrm{Cu}$ films further changed at $t_{\mathrm{Cu}}$ between 100 and $200 \mathrm{~nm}$. For $\mathrm{Ta} / \mathrm{Cu} / \mathrm{Ta}, d_{\mathrm{Cu} 111}$ was almost constant for $t_{\mathrm{Cu}}$ from 10 to $500 \mathrm{~nm}$ and larger by $\sim 0.3 \%$ than that of the bulk value. The values of $d_{\mathrm{Cu} 111}$ in $\mathrm{Ta} / \mathrm{Cu} / \mathrm{Ta}$ were slightly larger than those in $\mathrm{Ta} / \mathrm{Cu}$ at $t_{\mathrm{Cu}}$ between 10 and $30 \mathrm{~nm}$, at which the spontaneous improvement of the preferred (111) texture by the 5-nm-thick Ta capping was observed (Fig. 3(a)). The spontaneous improvement of the preferred (111) texture may have been responsible for the slightly larger $d_{\mathrm{Cu} 111}$ values in $\mathrm{Ta} / \mathrm{Cu} / \mathrm{Ta}$ at $t_{\mathrm{Cu}}$ between 10 and $30 \mathrm{~nm}$. In contrast, the increase in $d_{\mathrm{Cu} 111}$ by the 5 -nm-thick Ta capping was observed up to $t_{\mathrm{Cu}}$ of $\sim 80 \mathrm{~nm}$ in our previous studies ${ }^{4,15)}$ and indicates that the effects of the mixed Ta barrier composed of $\alpha$-Ta and $\beta$-Ta on the deposited $\mathrm{Cu}$ microstructures continued up to $t_{\mathrm{Cu}}$ of $80 \mathrm{~nm}$, as previously mentioned.

Figure 5(b) shows the $t_{\mathrm{Cu}}$ dependence of the interlayer distance for $\beta$-Ta (002) $\left(d_{\beta \mathrm{Ta} 002}\right)$ normal to the film surface, as determined from their respective XRD peak positions. The dotted/dashed line in Fig. 5(a) denotes a $d_{\beta \text { Ta002 }}$ of $268.65 \mathrm{pm}$ in the 35 -nm-thick Ta barrier alone. For the bulk value, a $d_{\beta \text { Ta002 }}$ of $266.4 \mathrm{pm}$ was reported for a $30-\mu \mathrm{m}$-thick $\beta$-Ta film deposited on an AISI4340 steel substrate, ${ }^{21)}$ whereas a value of $265.32 \mathrm{pm}$ was reported for a $\sim 20-\mu \mathrm{m}$ $\beta$-Ta single crystal. ${ }^{31)}$ The larger $d_{\beta \text { Ta002 }}$ as compared to the bulk values indicates that the present 35 -nm-thick $\beta$-Ta films sputter-deposited on $\mathrm{Si}(100)$ were in a compressed state along the surface of the film. The in-plane compressive strain (or stress) estimated for the 35-nm-thick $\beta$-Ta barrier alone ranged from 0.7 to $1.2 \%$ (or $1.3-2 \mathrm{GPa}$ ) using the bulk values of $d_{\beta \text { Ta002 }}$ mentioned above, a biaxial modulus of $175 \mathrm{GPa}$ for the $\beta$-Ta film along the (001) plane, ${ }^{32)}$ and a Poisson ratio of 0.3 . In $\mathrm{Cr}$ films (but not in $\beta$-Ta films) on $\mathrm{Si}$, the compressive stress was reported to have increased with decreasing film thickness $\left(t_{\mathrm{f}}\right) .{ }^{33)}$ Application of the filmthickness dependence of the internal stress reported in $\mathrm{Cr}$ films to the present case gave a compressive stress of $2.0 \mathrm{GPa}$ at a thickness of $35 \mathrm{~nm}$, exhibiting good agreement with the estimated compressive stress in the 35-nm-thick Ta barrier layer. On the other hand, the $d_{\beta \mathrm{Ta} 002}$ values of both $\mathrm{Ta} / \mathrm{Cu}$ and $\mathrm{Ta} / \mathrm{Cu} / \mathrm{Ta}$ decreased as compared to that of the Ta barrier alone (Fig. 5(b)). The in-plane compressive strain (or stress) of the barrier decreased to $0.4-0.7 \%$ (or $0.7-$ 
1.3 $\mathrm{GPa}$ ) after deposition of a $\mathrm{Cu}$ film, suggesting that there was a strong elastic interaction at the interface between the $\mathrm{Cu}$ film and the Ta barrier. The fcc $\mathrm{Cu}$ (111) plane has been reportedly grown heteroepitaxially on the $\beta$-Ta (002) plane with a lattice mismatch of $7.6 \%,{ }^{34)}$ and the interface between fcc $\mathrm{Cu}$ and $\beta$-Ta exhibited high thermal stability. ${ }^{18)}$ As previously mentioned for the SK growth mode of the $\mathrm{Cu}$ films on $\beta$-Ta, the formation of one conformal monolayer of $\mathrm{Cu}$ can decrease the in-plane compressive strain (or stress) in the Ta barrier and weaken the $\mathrm{Cu}$-thickness dependence of the $d_{\beta \mathrm{Ta} 002}$ values of both $\mathrm{Ta} / \mathrm{Cu}$ and $\mathrm{Ta} / \mathrm{Cu} / \mathrm{Ta}$, as shown in Fig. 5(b). A small local minimum observed at $t_{\mathrm{Cu}} \sim$ $100 \mathrm{~nm}$ for the $\mathrm{Cu}$-thickness dependence of the $d_{\beta \mathrm{Ta} 002}$ values may have been associated with a change in the growth mode of the $\mathrm{Cu}$ films (i.e., the transition from the (111) textured structure to the randomly textured structure began at $t_{\mathrm{Cu}}$ between 100 and $200 \mathrm{~nm}$ ).

Figure 5(c) shows the $\mathrm{Cu}$-thickness dependence of the mean grain size normal to the film surface $\left(D_{\mathrm{Cu} 111}\right)$, estimated from the width of the $\mathrm{Cu} 111$ reflection using the Scherrer equation. The instrumental line broadening was corrected from the 111 reflection observed for the $\mathrm{Cu}$ single crystal sample. The nearly identical $\mathrm{Cu}$-thickness dependence of $D_{\mathrm{Cu} 111}$ between $\mathrm{Ta} / \mathrm{Cu}$ and $\mathrm{Ta} / \mathrm{Cu} / \mathrm{Ta}$ supports the conclusion that the 5-nm-thick Ta capping did not cause grain growth but may have improved the alignment in the preferred (111) texture in $\mathrm{Cu}$ films by spontaneous rotational motion of the crystallites. As shown in Fig. 5(c), $D_{\mathrm{Cu} 111}$ was nearly identical to the $\mathrm{Cu}$ film thickness for $t_{\mathrm{Cu}}$ below $\sim 10 \mathrm{~nm}$, at which island-like $\mathrm{Cu}$ film growth following coverage with one conformal monolayer was expected, as mentioned previously. For $t_{\mathrm{Cu}}>10 \mathrm{~nm}$, the increase in $D_{\mathrm{Cu} 111}$ exhibited saturation at $\sim 30 \mathrm{~nm}$ for $t_{\mathrm{Cu}}>100 \mathrm{~nm}$ (Fig. 5(c)). At this $t_{\mathrm{Cu}}$, continuous $\mathrm{Cu}$ film growth in the SK mode and cessation of the effect of $\beta$-Ta barrier on the $\mathrm{Cu}$ film growth were likely. Then, the saturation of $D_{\mathrm{Cu} 111}$ at $\sim 30 \mathrm{~nm}$ for $t_{\mathrm{Cu}}>100 \mathrm{~nm}$ (Fig. 5(c)) suggests that the $\sim 30 \mathrm{~nm}$ crystallites were thermally stable in the present $\mathrm{Cu}$ films. The mean grain size in nanocrystalline $\mathrm{Cu}$ with the preferred (111) texture prepared by various methods have been commonly reported at $25-30 \mathrm{~nm}^{25,35)}$ That is, constituent nanocrystallites with grain sizes of $25-30 \mathrm{~nm}$ were in a quasi-stable state in nanocrystalline $\mathrm{Cu}$ with the preferred (111) texture. Very similar results for the grain size stabilization in nanostructured fcc metals with the preferred (111) texture have been found in $n$-Au. ${ }^{24,36)}$ In contrast, in the nanocrystalline $\mathrm{Cu}$ films deposited on the mixed Ta barrier composed of $\alpha$-Ta and $\beta$-Ta, the mean grain size increased beyond $30 \mathrm{~nm}$ and exhibited a poorly preferred (111) texture.,15) This again suggests that the effects of the mixed Ta barrier composed of $\alpha$-Ta and $\beta$-Ta on the deposited $\mathrm{Cu}$ crystallites continued up to $t_{\mathrm{Cu}}$ of $80 \mathrm{~nm}$.

\section{Conclusion}

$\mathrm{Cu}$ films were sputter-deposited on 35-nm-thick $\beta$-Ta barrier films, and changes in their texture as a function of $\mathrm{Cu}$ thickness and by 5-nm-thick Ta capping were investigated. For the $\mathrm{Cu}$-thickness $\left(t_{\mathrm{Cu}}\right)<100 \mathrm{~nm}$, all $\mathrm{Cu}$ films exhibited a highly preferred (111) texture in which the (111) planes of most crystallites were parallel to the flat surface of the sample. For $\mathrm{Cu}$ films without Ta capping $(\mathrm{Ta} / \mathrm{Cu})$, the $\mathrm{Cu}-$ thickness dependence of the integral intensity of the 111 reflection exhibited a step-like increase at $t_{\mathrm{Cu}}$ between 22 and $33 \mathrm{~nm}$, indicating spontaneous improvement of the preferred (111) texture in the already-deposited $\mathrm{Cu}$ films by subsequent deposition of $\mathrm{Cu}(\mathrm{Cu}$ self-capping effect). For $\mathrm{Cu}$ films with the 5-nm-thick Ta capping $(\mathrm{Ta} / \mathrm{Cu} / \mathrm{Ta})$, the spontaneous improvement of the preferred (111) texture in the alreadydeposited $\mathrm{Cu}$ films by 5 -nm-thick Ta capping occurred at $t_{\mathrm{Cu}}$ between 10 and $30 \mathrm{~nm}$ (Ta capping effect). Both these effects were associated with spontaneous rotational motion of the $\mathrm{Cu}$ crystallites. For creep deformations (but not for film deposition), such spontaneous rotational motion of the crystallites has been reported in nanocrystalline $\mathrm{Cu}$ and nanocrystalline $\mathrm{Au}$. In the present study, reduction in the total surface and interface energies caused self-adjustment of the crystallographic directions in the already-deposited $\mathrm{Cu}$ films. The mean grain size in the $\mathrm{Cu}$ films with the preferred (111) texture deposited on $\beta$-Ta barrier films exhibited saturation at $\sim 30 \mathrm{~nm}$, whereas that in the $\mathrm{Cu}$ films with a poorly preferred (111) texture deposited on the mixed Ta barrier composed of $\alpha$-Ta and $\beta$-Ta increased beyond $30 \mathrm{~nm}$, as reported in previous works. These observations indicate that grain sizes of $25-30 \mathrm{~nm}$ were in a quasi-stable state in nanocrystalline $\mathrm{Cu}$ with the preferred (111) texture.

The present experimental results indicate the following model for the microstructural evolution of nanometer $\mathrm{Cu}$ films deposited on $\beta$-Ta barrier. At the initial stage of $\mathrm{Cu}$ deposition, one conformal $\mathrm{Cu}$ monolayer was formed on the $\beta$-Ta barrier, and it decreased the in-plane compressive strain (or stress) in the $\beta$-Ta barrier on the $\mathrm{Si}(100)$ substrate. Then, isolated island growth of $\mathrm{Cu}$ occurred with increasing deposited $\mathrm{Cu}$ thickness up to $\sim 10 \mathrm{~nm}$, where the degree of the preferred (111) texture in the $\mathrm{Cu}$ films remained poor, and neither $\mathrm{Cu}$ self-capping effects nor Ta capping effects were expected. Above a $\mathrm{Cu}$ thickness of $\sim 10 \mathrm{~nm}$, the isolated islands coalesced and formed a continuous film, where the degree of the preferred (111) texture in the $\mathrm{Cu}$ films improved, and both $\mathrm{Cu}$ self-capping effects and Ta capping effects were expected. After saturation of the enhanced preferred (111) texture in the $\mathrm{Cu}$ films for a $\mathrm{Cu}$ thickness of $\sim 30 \mathrm{~nm}$, both $\mathrm{Cu}$ self-capping effects and Ta capping effects disappeared. The present results reemphasize the technological scientific importance of a controlled interface and grain boundaries for nanometer-sized devices.

\section{Acknowledgement}

This study was financially supported by a Grant-in-Aid for Scientific Research from the Japan Society for the Promotion of Science.

\section{REFERENCES}

1) H. Mizubayashi, K. Goto, T. Ebisawa and H. Tanimoto: Mater. Sci. Eng. A 442 (2006) 342.

2) V. Timoshevskii, Y. Ke, H. Guo and D. Gall: J. Appl. Phys. 103 (2008) 113705.

3) F. Zahid, Y. Ke, D. Gall and H. Guo: Phys. Rev. B 81 (2010) 045406

4) K. Fujiwara, H. Tanimoto and H. Mizubayashi: Mater. Sci. Eng. A 442 
(2006) 336.

5) A. Hashibon, C. Elsässer, Y. Mishin and P. Gumbsch: Phys. Rev. B 76 (2007) 245434.

6) P. A. Gruber, J. Böhm, F. Onuseit, A. Wanner, R. Spolenak and E. Arzt: Acta Mater. 56 (2008) 2318.

7) L. Chen, N. Magtoto, B. Ekstrom and J. Kelber: Thin Solid Films 376 (2000) 115.

8) X. Zhao, M. Leavy, N. P. Magtoto and J. A. Kelber: Appl. Phys. Lett. 79 (2001) 3479.

9) K. Abe, Y. Harada, M. Yoshimaru and H. Onoda: J. Vac. Sci. Technol. B 22 (2004) 721.

10) I. Lazic, P. Klaver and B. Thijsse: Phys. Rev. B 81 (2010) 045410.

11) W. K. Kuhn, R. A. Campbell and D. W. Goodman: J. Phys. Chem. 97 (1993) 446.

12) F. Fillot, Zs. Tökei and G. P. Beyer: Surf. Sci. 601 (2007) 986.

13) T. P. C. Klaver and B. J. Thijsse: J. Computer-Aided Mater. Design 10 (2003) 61.

14) A. Hashibon, A. Y. Lozovoi, Y. Mishin, C. Elsässer and P. Gumbsch: Phys. Rev. B 77 (2008) 094131.

15) H. Tanimoto, K. Fujiwara and H. Mizubayashi: Sci. Technol. Adv. Mater. 6 (2005) 620.

16) B. S. Berry and A. C. Pritchet: J. Physique (Paris) 42 (1981) C5-1111.

17) H. Mizubayashi, Y. Yoshihara and S. Okuda: Phys. Status Solidi (a) 129 (1992) 475.

18) K.-W. Kwon, H.-J. Lee and R. Sinclair: Appl. Phys. Lett. 75 (1999) 935.

19) H. Donohue, J. C. Yeoh, K. Giles and K. Buchanan: Micro. Eng. 64 (2002) 299.

20) S. Kohli, P. R. McCurdy, C. D. Rithner, P. K. Dorhout, A. M. Dummer, F. Brizuela and C. S. Menoni: Thin Solid Films 404 (2004) 469.
21) A. Jiang, T. A. Tysona, L. Axe, L. Gladczuk, M. Sosnowski and P. Cote: Thin Solid Films 479 (2005) 166.

22) J. W. Bae, J.-W. Lim, K. Mimura and M. Isshiki: Thin Solid Films 515 (2007) 4768

23) B. D. Cullity: Elements of X-ray Diffraction, 2nd ed., (AddisonWesley, Massachusetts, 1978) pp. 4-10.

24) N. Yagi, A. Rikukawa, H. Mizubayashi and H. Tanimoto: Phys. Rev. B 74 (2006) 144105.

25) N. Yagi: Dr. Thesis, Institute of Materials Science, University of Tsukuba (2007).

26) G. C. A. M. Janssen: Thin Solid Films 515 (2007) 6654.

27) F. Spaepen: Acta Mater. 48 (2000) 31.

28) Smithells Metals Reference Book, 7th ed., ed. by E. A. Brandes and G. B. Brook, (Butterworth-Heinemann, Oxford, 1992) Chap. 15, p. 15-2.

29) J. A. Floro, S. J. Hearne, J. A. Hunter, P. Kotula, E. Chason, S. C. Seel and C. V. Thompson: J. Appl. Phys. 89 (2001) 4886.

30) W. D. Nix and B. M. Clemens: J. Mater. Res. 14 (1999) 3467.

31) A. Arakcheeva, G. Chapuisa and V. Grinevitch: Acta Cryst. B 57 (2002) 1 .

32) R. Knepper and S. P. Baker: Appl. Phys. Lett. 90 (2007) 181908.

33) G. C. A. M. Janssen and J.-D. Kamminga: Appl. Phys. Lett. 85 (2004) 3086 .

34) K.-W. Kwon, C. Ryu, R. Sinclair and S. S. Wong: Appl. Phys. Lett. 71 (1997) 3069.

35) B. Cai, Q. P. Kong, L. Lu and K. Lu: Mater. Sci. Eng. A 286 (2000) 188.

36) H. Tanimoto, K. Mutou, Y. Hosonuma, K. Yamamoto and H. Mizubayashi: Mater. Sci. Eng. A 521-522 (2009) 295. 